\title{
Danos causados por gado leiteiro no componente arbóreo de um sistema silvipastoril ${ }^{1}$
}

\author{
Eleandro José Brun²; David Marlon Dalposso $;$; Fernando Kuss ${ }^{4}$ Laércio Ricardo Sartor ${ }^{5}$; Flávia Gizele \\ Konig Brun ${ }^{6}$; Cláudia Dyana Santos Peretiatko ${ }^{7}$
}

Resumo: O estudo teve como objetivo quantificar os danos causados por gado leiteiro sobre o crescimento e capacidade de recuperação das árvores do híbrido Eucalyptus grandis x E. camaldulensis (grancam) em um sistema silvipastoril experimental, implantado em outubro/2012, após a soltura de animais na área, no inverno/2014. O delineamento constituiuse em esquema bifatorial, considerando: a distância entre a entrada dos animais na área com as linhas duplas de plantio (fator 1) e as duas ocasiões de avaliação (fevereiro/2015 e julho/2016) (fator 2). Assim, classificaram-se os níveis de danos (baixo/médio/alto) e avaliou-se a interferência dos mesmos no crescimento em diâmetro à altura do peito (DAP) e altura total (Ht), bem como a capacidade de recuperação das árvores. Verificou-se, como resultados que, não houve interação significativa entre o fator 1 e 2 para DAP; as árvores das linhas mais próximas ao local de entrada dos animais na área apresentaram menor DAP $(19,7$ e 20,6 cm) em relação às linhas mais distantes $(26,1$ e 23,9 cm). A partir disso tem-se que, a interação foi significativa para $\mathrm{Ht}$, mas sem diferença significativa entre as linhas. Já, entre as duas avaliações ocorreu incremento médio geral de 2,59 $\mathrm{cm} \mathrm{ano}^{-1} \mathrm{em} \mathrm{DAP} \mathrm{e,} \mathrm{em} \mathrm{Ht} \mathrm{de} \mathrm{5,9} \mathrm{e} \mathrm{6,0} \mathrm{m} \mathrm{ano-1,} \mathrm{nas} \mathrm{linhas} 2$ e 4; superiores aos 4,6 e 4,4 $\mathrm{m}^{-1} \mathrm{eno}^{-1}$, nas linhas 1 e 3, respectivamente. Em relação ao período de 2015/2016 examinou-se que, em 2015 a maioria das árvores apresentou danos de nível alto (65\%), caindo para 6,7\% em 2016, evidenciando a capacidade de recuperação do Grancam. Por fim, verificouse que ocorreu correlação significativa inversa entre DAP e Ht, com danos de nível alto ( $r=-0,25$ e - 0,24 , respectivamente), mostrando que as árvores pequenas são mais susceptíveis aos danos causados pelos bovinos.

Palavras-chave: Sistemas Integrados de Produção; Eucalipto; Sistemas Agroflorestais.

\section{Dairy cattle damage in the arboreal component of a silvopastoral system}

\begin{abstract}
The study aimed to quantify the damage caused by dairy cattle on the growth and recovery capacity of hybrid Eucalyptus grandis x E. camaldulensis (grancam) trees in a experimental silvopastoral system implanted in October/2012, after release of animals in the area in winter/2014. The experimental design consisted of a two-factor scheme, considering the distance between the animals entering the area and the double planting lines (factor 1) and the two evaluation occasions (February / 2015 and July / 2016) (factor 2). The damage levels (low / medium / high) were classified and their interference on growth in diameter at breast height $(\mathrm{DBH})$ and total height $(\mathrm{Ht})$, as well as the recovery capacity of the trees were evaluated. There was no significant interaction between factor 1 and 2 for DBH. The trees of the lines closest to the place of entry of the animals in the area showed a lower DBH $(19.7$ and $20.6 \mathrm{~cm})$ in relation to the furthest lines $(26.1$ and $23.9 \mathrm{~cm})$. The interaction was significant for $\mathrm{Ht}$, but not significant difference between the lines. At the two evaluations, there was a general average increase of $2.59 \mathrm{~cm}_{\text {year }}{ }^{-1}$ in DBH and, in Ht, of 5.9 and $6.0 \mathrm{~m}^{\text {in year }}{ }^{-1}$ in lines 2 and 4, 4.6 and $4.4 \mathrm{~m}_{\text {year }}{ }^{-1}$ in lines 1 and 3, respectively. In 2015, most of the trees presented high-level of damage (65\%), falling to $6.7 \%$ in 2016 , showing the recuperation capacity of grancam. There was a significant inverse correlation between DBH and $\mathrm{Ht}$ with high level of damage $(r=-0.25$ and -0.24 , respectively), showing that small trees are more susceptible to damage by cattle.
\end{abstract}

Keywords: Integrated Production System; Eucalyptus; Agroforest Systems.

\footnotetext{
${ }^{1}$ Recebido em 17.01.2017 e aceito para publicação como artigo científico em 07.06.2017.

${ }^{2}$ Engenheiro Florestal, Dr. Professor da Universidade Tecnológica Federal do Paraná - Campus Dois Vizinhos, Programa de Pós-graduação em Agroecossistemas (PPGSIS). E-mail: <eleandrobrun@utfpr.edu.br>.

${ }^{3}$ Engenheiro Florestal. Mestre, Consultor Agroflorestal. E-mail: <david_marlondalposso@ hotmail. com>.

4 Zootecnista, Dr. Professor Adjunto da Universidade Tecnológica Federal do Paraná - Campus Dois Vizinhos. E-mail: $<$ fernandokuss@utfpr.edu.br>.

${ }^{5}$ Engenheiro Agrônomo, Dr. Professor Adjunto da Universidade Tecnológica Federal do Paraná - Campus Dois Vizinhos, PPGSIS. E-mail: <laerciosartor@utfpr.edu.br>.

${ }^{6}$ Engenheira Florestal, Dra. Professora Adjunta da Universidade Tecnológica Federal do Paraná - Campus Dois Vizinhos. E-mail: <flaviag@utfpr.edu.br>.

${ }^{7}$ Licenciada em Química, Esp. em Manejo da Fertilidade do Solo, Universidade Tecnológica Federal do Paraná - Campus Dois Vizinhos E-mail<claudiadstc@yahoo.com.br>.
} 


\section{Introdução}

O sistema silvipastoril é um dos tipos de sistemas agroflorestais (SAF's) que integram espécies arbóreas e pastagens em uma mesma área, de forma simultânea; tal sistema permite o uso sustentável da terra e dos recursos naturais (CARVALHO et al., 1995), promovendo o aumento ou a manutenção da produtividade, com conservação dos recursos naturais e a utilização mínima de insumos.

Apesar de vários estudos mostrarem os benefícios da inclusão de árvores em pastagens, como: a melhoria da beleza cênica da paisagem, os efeitos microclimáticos, a qualidade do solo, o bem-estar animal, a qualidade da forragem e a mitigação de gases de efeito estufa (CARVALHO et al., 2001), ainda são limitadas as informações sobre o manejo dos vários componentes específicos em sistemas de ILPF (Integração-Lavoura-Pecuária-Floresta).

Quando há uma harmonia entre os três fatores dos sistemas silvipastoris: a árvore, o ruminante e a pastagem, pode-se esperar o sucesso do sistema, com uma produção satisfatória da pastagem, do ruminante e da floresta. Mas, algumas dificuldades ainda são encontradas nos requisitos de manejo, entre eles: o espaçamento entre as árvores, a concentração de animais na área e as espécies forrageiras utilizadas (VARELLA et al., 2016).

Para escolher as forrageiras é preciso avaliar e selecionar genótipos que se adaptem a locais sombreados e ao clima da região onde se aplica o sistema. Com relação ao espaçamento entre as plantas arbóreas, este deve ser determinado a ponto de permitir que o sol penetre entre as copas das árvores e leve iluminação solar até o dossel da forrageira. Em estudo realizado numa área em Alegrete/RS, os espaçamentos de $3 \mathrm{~m} \times 1,5 \mathrm{~m} \mathrm{x}$ $14 \mathrm{~m}$, proporcionaram $30 \%$ de luminosidade e ( 3 $\mathrm{m} \times 1,5 \mathrm{~m} \times 34 \mathrm{~m}$ ) proporcionaram $65 \%$ de luminosidade para a forrageira, numa média para eucalipto e pinus (VARELLA et al., 2016).

Essas variáveis devem ser observadas para evitar danos dos animais às plantas. Alguns danos mostram-se de pequena monta ou até mesmo pequenos a ponto de não interferir no crescimento da planta, desde que a árvore tenha porte suficiente para suportar o assédio dos animais, uma vez que, ao se alimentarem da casca das árvores, a planta fica susceptível e pode ser atacada por doenças como fungos e também por insetos que podem promover o apodrecimento do tronco (PORFÍRIO-DASILVA et al., 2009).

Forrageiras herbáceas, especialmente gramíneas, são a principal fonte de alimentos para bovinos, embora esses animais apreciem maior variedade em sua dieta (SANTOS et al., 2002; USDA, 2005). Em ambiente pastoril onde existam árvores, os animais vão consumir pequenas quantidades de ramos e de folhas a cada dia, se estas estiverem acessíveis (FIKE et al., 2004). Tal consumo pode se tornar prejudicial ao sistema silvipastoril quando a pequena quantidade de ingestão diária, acumulada, atinge níveis significativos de danos, ocasionando prejuízo no crescimento das árvores.

A exposição do lenho propicia o ataque de fungos e insetos xilófagos que podem promover o apodrecimento e provocar a quebra do tronco. Efeitos conhecidos como a acumulação de fotoassimilados acima da área lesionada (LI et al., 2003) e esgotamento das reservas de amido da raiz (HÖGBERG et al., 2001), podem provocar o aumento temporário da respiração do solo (NORDGREN et al., 2003). A acumulação de fotoassimilados, como amido, acima da região onde a casca foi mastigada (roída) pode intensificar as chances de a árvore ser novamente procurada pelos animais, resultando em danos crescentes e mortalidade da árvore.

O presente trabalho teve por objetivo quantificar os danos causados por gado leiteiro sobre o crescimento e capacidade de recuperação das árvores de eucalipto híbrido Eucalyptus grandis $\mathrm{x}$ E. camaldulensis em um sistema silvipastoril.

\section{Material e métodos}

O município de Dois Vizinhos está localizado na região Sudoeste do Estado do Paraná, com 
altitude média de 509 metros, latitudes $25^{\circ} 45^{\prime}$ 04" Sul e longitudes 53 $3^{\circ}$ 03' 05" Oeste. De acordo com a classificação climática de Koppen (ALVARES et al., 2013), o tipo de clima que ocorre em Dois Vizinhos é o Cfa, sendo subtropical, sem estação seca definida, com temperatura média do mês mais frio menor que $18{ }^{\circ} \mathrm{C}$ e temperatura média do mês mais quente maior que $22{ }^{\circ} \mathrm{C}$, com temperatura média anual igual a $19^{\circ} \mathrm{C}$. A precipitação média anual é de cerca de $2.050 \mathrm{~mm}$.

O solo da área de estudo foi classificado por Cabreira (2015), como: Nitossolo Vermelho distroférrico, esse apresenta horizonte $\mathrm{B}$ nítico abaixo do horizonte A com argila de atividade baixa ou caráter alítico na maior parte do horizonte $\mathrm{B}$, estrutura em blocos subangulares ou angulares, ou prismática, de grau moderado ou forte, com cerosidade expressiva nas superfícies dos agregados. São, em geral, moderadamente ácidos a ácidos (EMBRAPA, 2013).

A área de sistema silvipastoril foi instalada na Estação Experimental da UTFPR Dois Vizinhos, em outubro de 2012. Para o estabelecimento da espécie arbórea foram implantadas mudas clonais do híbrido de Eucalyptus grandis x $E$. camaldulensis. O preparo do solo foi realizado com escarificador de 5 hastes a uma profundidade média de 30 centímetros nos renques de plantio. A distribuição das árvores foi realizada em renques duplos com espaçamento 3 $\mathrm{m} \times 2 \mathrm{~m}$. Os quatro renques duplos foram espaçados 23 metros entre si, em uma área total de 3,7 ha.

No plantio aplicou-se solução de hidrogel, na dose de $1 \mathrm{~kg}$ do produto para 400 litros de água, sendo que para cada muda, na cova, foi utilizada a quantidade de $300 \mathrm{~mL}$. A área teve a correção de acidez, 6 meses antes da implantação do experimento, com a aplicação de 2,5 $\mathrm{t} \mathrm{ha}^{-1} \mathrm{de}$ calcário dolomítico. A adubação com NPK foi aplicada, em uma única dose, 30 dias após o plantio, em sistema de coveta lateral, na dosagem recomendada pela análise de solo, com $50 \mathrm{~g}$ de Ureia $(45 \% \mathrm{~N}), 42 \mathrm{~g}$ de $\mathrm{P}_{2} \mathrm{O}_{5}$ (Superfosfato Triplo) e $91 \mathrm{~g}$ de Cloreto de Potássio $\left(58 \% \mathrm{~K}_{2} \mathrm{O}\right)$ para cada planta.
No desenvolvimento da área de produção integrada, entre os renques de Grancam foi cultivado soja na primavera/verão (outubro/2012 a março/2013). No outono/inverno seguinte (abril a setembro/2013) foi plantada aveia-preta, pastejada por vacas leiteiras, entre maio e agosto/2013, numa lotação média de 10 animais ha $^{-1}$, entre os renques de eucalipto, os quais estavam protegidos dos animais por cerca elétrica. No período de primavera/verão (outubro/2013 a março/2014) foi novamente cultivado soja. No outono e inverno de 2014 (abril a setembro) foi cultivada novamente aveia preta, pastejada por vacas leiteiras numa lotação média de 10 animais/ha, entre maio e julho/2014, período em que, por descuido do responsável pela área experimental, a cerca elétrica permaneceu desligada. Com isso, os bovinos tiveram acesso às árvores de eucalipto. Os danos resultantes do acesso dos animais foram diversos, tais como consumo de folhas, quebra de galhos, descascamentos e mastigação de cascas dos troncos, entre outros danos.

Após o dano às árvores, o gado foi retirado da área e a mesma foi cultivada com milho na primavera (setembro) e verão (fevereiro) de 2014/2015, visando a recuperação do componente arbóreo. Também nesse momento foi realizada uma desrama das árvores, até 50\% da altura total das mesmas, o que correspondeu a uma altura de desrama entre 4 e $5 \mathrm{~m}$.

No outono (maio/2015) foi semeada pastagem perene de capim aruana (Panicum maximum cv. aruana), não tendo ocorrido pastejo nessa estação, somente na primavera e verão (setembro/2015 a fevereiro/2016), após as árvores já terem apresentado um certo nível de recuperação do dano sofrido anteriormente. No outono/inverno (março a agosto/2016) ocorreu sobressemeadura de aveia sobre a pastagem de capim aruana e o pastejo de vacas leiteiras da raça holandesa, com 10 animais ha ${ }^{-1}$, lotação em acordo com as recomendações zootécnicas de pastejo para pastagens cultivadas.

A coleta de dados foi realizada em fevereiro de 2015 (sete meses após a ocorrência do dano) quando o plantio se encontrava com 28 meses de 
idade, e em julho de 2016 (24 meses após o dano), quando o plantio estava com 45 meses de idade. $\mathrm{O}$ experimento foi planejado em esquema bifatorial, sendo o fator 1 a distância de cada renque ao local de entrada dos animais na área (4 níveis) e o fator 2 o ano de avaliação (2 níveis). Cada árvore foi considerada uma repetição.

Os níveis do fator 1 foram delimitados com base na distribuição das árvores na área, com as medições sendo feitas em 4 renques ( $3 \mathrm{~m} \mathrm{x} 2 \mathrm{~m}$ ), distanciadas $23 \mathrm{~m}$ entre si (considerados em função da distância do local de entrada do gado na área, sendo: L1: $0 \mathrm{~m}$ (em frente a primeira linha dupla); L2: 25 m; L3:50 m e L4: 75 m de distância do ponto de entrada do gado leiteiro na área). Os níveis do fator 2 foram a comparação dos dados entre os dois anos de estudo (2015 e 2016).

Em todas as árvores dessas linhas foram levantadas as informações referentes à CAP (Circunferência à Altura do Peito) e altura total (Ht); ocorrência e nível de danos causados pelo gado, considerando nível 1 (baixo), nível 2 (médio) e nível 3 (alto). Os CAPs das árvores foram aferidos com o auxílio de fita métrica e depois transformados em DAP. Além disso foi mensurada a altura total através de Hipsômetro Vertex III.

Os níveis de danos causados pelos animais na área em estudo foram classificados da seguinte maneira (Figura 1): Dano nível 1: Dano pequeno ou inexistente, apenas em partes menores de cascas ou galhos; Dano nível 2: Dano nível médio, arrancamento ou remoção de cascas em tiras maiores, galhos e folhas; Dano nível 3: Dano nível alto, arrancamento e/ou mastigação de grandes pedaços de casca, expondo o lenho, ocorrendo quebra de troncos menores e galhos.

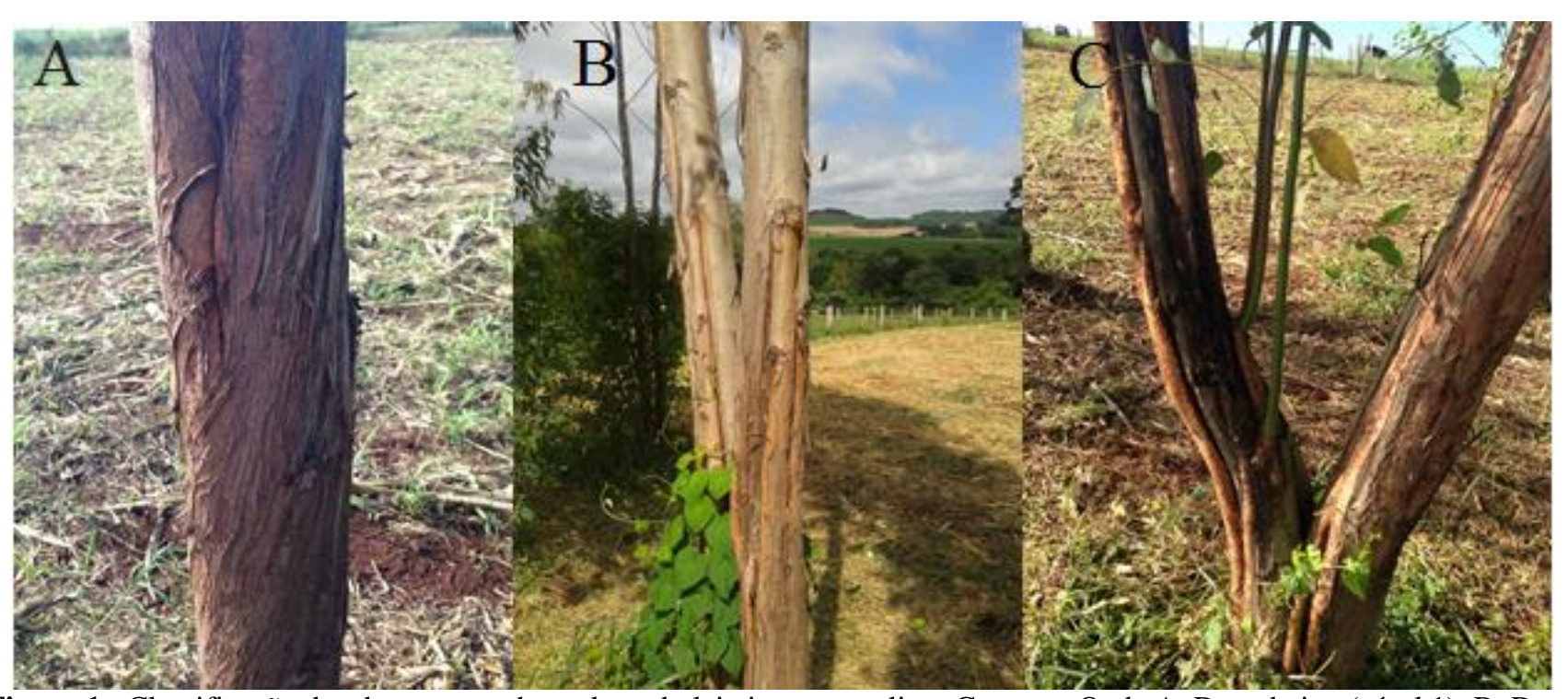

Figura 1 - Classificação dos danos causados pelo gado leiteiro no eucalipto Grancan. Onde A: Dano baixo (nível 1); B: Dano médio (nível 2); C: Dano alto (nível 3).

Figure 1 - Classification of damage caused by dairy cattle in the Grancan eucalyptus. Where A: Damage level 1; B: damage level 2 and, C: Damage level 3.

Os dados foram tabulados em planilhas Excel (B) e submetidos ao teste de normalidade por Shapiro Willk, com posterior análise de variância, teste de comparação de médias e análise de correlação entre variáveis dendrométricas e nível de danos. Para a análise estatística dos dados utilizou-se o software estatístico Assistat versão 7.7 (SILVA et al., 2016).

\section{Resultados e Discussão}

Todos os dados de DAP, altura total, nível e 
distribuição dos danos apresentaram distribuição normal, não necessitando de transformação. Para a variável DAP, a interação entre os fatores 1 (distância da entrada de animais) e 2 (ano de avaliação) não foi significativa, sendo apresentados os resultados dos fatores em separado.

Com base na Tabela 1, verificam-se diferenças significativas para as distâncias entre as linhas de plantio e o local de entrada dos animais na área. Os tratamentos L1 e L2, distanciados de 0 a 25 metros, respectivamente, apresentaram os menores valores de DAP em relação à $\mathrm{L} 3$, a $50 \mathrm{~m}$, e também $\mathrm{L} 4$, a $75 \mathrm{~m}$ de distância, com valores intermediários.

Tabela 1 - Valores médios de diâmetro à altura do peito (DAP, $\mathrm{cm}$ ) em função da distância das linhas duplas de plantio de Grancam e o ponto de entrada de animais na área e nos dois diferentes anos de avaliação.

Table 1 - Average values of diameter at breast height $(\mathrm{cm})$ in function of the distance of the double lines of Grancam planting and the place of animal entrance in the area and in the different years of study.

\begin{tabular}{cccc}
\hline Distâncias (m) da entrada dos animais & DAP (cm) & Ano & DAP (cm) \\
\hline L1 (0) & $19,70 \mathrm{~B} *$ & 2015 & $20,75 \mathrm{~B}$ \\
L2 (25) & $20,64 \mathrm{~B}$ & 2016 & - \\
L3 (50) & $26,15 \mathrm{~A}$ & - & - \\
L4 (75) & $23,85 \mathrm{AB}$ & - & 2,59 \\
\hline Dms & 4,82 & - &
\end{tabular}

* Médias seguidas pelas mesmas letras, na vertical, não diferem estatisticamente entre si pelo Teste de Tukey a 1\% de probabilidade de erro. Dms: diferença mínima significativa.

* Average follow by the same letters, in vertical, do not differ by the Tukey test at $1 \%$ of error probability. Dms: minimum significant difference.

Esses resultados podem ser explicados pelo comportamento dos animais, de se concentrarem em maior densidade nos locais mais próximos à entrada na área, com contato mais frequente com as árvores mais próximas da entrada para o pastejo, com níveis de danos prejudiciais aos indivíduos destes tratamentos, causando danos mais intensos (exposição do lenho e quebra de galhos), a ponto de prejudicar o desenvolvimento em DAP das árvores. Mesmo assim, apesar do menor nível de dano, a L4 apresentou DAP intermediário, não diferindo estatisticamente das demais, fato que pode estar relacionado a menor qualidade do solo na área, visivelmente perceptível pela presença de pedras na superfície, denotando solo de menor profundidade.

A perda de folhas em função dos galhos quebrados e a exposição do lenho influenciou no processo de fotossíntese (menor área foliar para captação de luz), diminuindo a quantidade de fotoassimilados produzidos pela árvore e também havendo um maior direcionamento dos mesmos para a recuperação das lesões sofridas (formação de calos e intensificação da divisão celular no entorno das lesões, visando recobrilas e proteger as partes internas do tronco anteriormente expostas), afetando, consequentemente, o crescimento em diâmetro dos indivíduos.

Situações como estas são explicadas pela dependência da fotossíntese, em termos de fatores limitantes, principalmente, por luz e concentração de $\mathrm{CO}_{2}$ (TAIZ e ZEIGER, 2004). Em condição de suprimento similar desses fatores em ambos os tratamentos, a limitação se dá pela menor captação dos mesmos nas árvores com área foliar diminuída em função do estresse sofrido devido aos danos pelos animais (perda de área foliar), o que causa menor absorção de luz e $\mathrm{CO}_{2}$ e, consequentemente, de transformação dos fotoassimilados em carboidratos. Além disso, em uma situação de estresse, há um direcionamento da energia obtida via fotossíntese e também da absorção via sistema radicular visando o recobrimento e a 
recuperação mais rápida possível da lesão (Li et al., 2003), com um conhecido acúmulo de carboidratos acima da região lesionada e necessidade de defesa contra pragas e doenças nas áreas lesionadas (FERREIRA e MILANI, 2004).

Quando foram comparados os valores de DAP nos diferentes anos de avaliação, obteve-se o maior valor para o ano de 2016, fato já esperado em virtude do crescimento ocorrido durante os 17 meses de tempo entre as duas avaliações (fevereiro/2015 a julho/2016). Tal fato demonstra a rusticidade e boa adaptação do híbrido Grancam às condições edafoclimáticas da região Sudoeste do Paraná e do seu potencial para compor sistemas silvipastoris, uma vez que, apesar do dispêndio de energia para a recuperação dos danos sofridos pela ação do gado leiteiro, em média, ainda ocorreu o incremento de 2,59 $\mathrm{cm} \mathrm{ano}^{-1}$ em DAP, algo similar a outros plantios de Eucalyptus sp. na região.

Como comparação que provam as afirmações do parágrafo anterior, cabe citar o trabalho de Dorini Jr. (2015), que estudou 10 materiais genéticos de Eucalyptus sp. com 5 anos de idade, também plantados na Estação Experimental da UTFPR em Dois Vizinhos-PR, o qual reportou incrementos médios anuais em DAP entre 2,7 (E. pellita) e 4,9 cm (E. urograndis, clone H13), estando em meia a esse intervalo os materiais $E$. pellita x E. tereticornis, Clone GFMO-27, E. propinqua, E. urophylla x E. grandis, Clone I224, E. saligna x E. botryoides, E. camaldulensis e E. urophylla clone floração.

Também cabe citar o trabalho de Habitzreiter (2016), que obteve incrementos médios anuais de 2,5 e 2,6 cm em DAP para Eucalyptus grandis e E. urophylla em plantio com 5 anos de idade, no município de Salto do Lontra-PR, a cerca de $25 \mathrm{~km}$ da área desse estudo.

Para a variável altura total, ocorreu interação significativa pela análise de variância, mostrando a inter-relação entre a distância do local de entrada dos animais até as linhas duplas de plantio e os anos de avaliação (Tabela 2). Na avaliação realizada em fevereiro de 2015 , cerca de 6 meses após os danos terem sido realizados nas árvores pelo gado, as quatro linhas duplas não apresentaram alturas estatisticamente diferentes entre si, o que ocorreu na avaliação de julho de 2016, aproximadamente 2 anos (23 meses) após os danos.

Apesar disso, não se pode afirmar a existência de uma relação direta entre os níveis de danos e a variação do crescimento em altura, algo que deve estar mais associado a diferenças intraespecíficas de sítio na área experimental, uma vez que, conforme Schneider (2004), o crescimento em altura é influenciado predominantemente pela qualidade do sítio onde a árvore ocorre e não pela concorrência, como poderiam ser enquadrados os danos causados pelos animais.

Em todos os tratamentos ocorreu um bom incremento em altura do híbrido Grancam, alcançando $6,0 \mathrm{~m} \mathrm{ano}^{-1}$ na linha 4 e 5,9 $\mathrm{m} \mathrm{ano}^{-1}$ na linha 2, valores esses considerados elevados, conforme o potencial de crescimento do híbrido. Considerando que, na avaliação de 2015, o plantio encontrava-se com 28 meses de idade, o crescimento ocorrido foi similar ao encontrado por Borges et al. (2012), em estudo realizado com o mesmo híbrido, com 25 meses de idade, em sistema silvipastoril implantado em Votuporanga-SP, que alcançou 11,4 m.

Porém, na avaliação de 2016, quando o plantio se encontrava com 45 meses de idade, o crescimento foi relativamente inferior ao encontrado por Ferreira et al. (2014), para o híbrido urograndis em Avaré-SP, aos 48 meses de idade, em espaçamento $3 \mathrm{~m}$ x $2 \mathrm{~m}$, que alcançou $20 \mathrm{~m}$ de altura total média. Também, Oliveira et al. (2014), ao estudarem o crescimento do Grancam em Aquidauana-MS, relataram que o híbrido alcançou uma altura total de $17,8 \mathrm{~m}$ aos 37 meses de idade, muito similar ao presente estudo.

Em sistema agrosilvipastoril com Grancam com 3,6 anos, plantado em Votuporanga/SP, os resultados de crescimento mostraram cerca de 19 $\mathrm{m}$ de altura total média, alcançando valores semelhantes ao presente estudo, já aos 3,6 anos (BORGES et al., 2014).

Aos quatro anos de idade, o eucalipto Grancam plantado em diferentes sistemas 
(monocultural (3 $\mathrm{m} \quad \mathrm{x} \quad 2 \mathrm{~m})$ e em dois espaçamentos de sistema silvipastoril, em renques de 24 e $42 \mathrm{~m}$ de distância), teve crescimento em altura superior no renque de 24 m (17,7 m), seguido do renque de $42 \mathrm{~m}(17,3 \mathrm{~m})$ e do plantio puro $(15,9 \mathrm{~m})$ (RIBEIRO e RIGUI, 2016).

Tabela 2 - Variação da altura total em função da interação entre a distância do local de entrada dos animais na área até as linhas de plantio e os anos de avaliação.

Table 2 - Total height variation in function of the interaction between the distance of the animal entrance in the area and the years of evaluation.

\begin{tabular}{|c|c|c|c|}
\hline \multirow{2}{*}{$\begin{array}{c}\text { Fator } 1- \\
\text { Distâncias (m) da entrada dos animais }\end{array}$} & \multicolumn{2}{|c|}{ Fator 2 - Ano de avaliação } & \multirow{2}{*}{$\begin{array}{c}\text { IMA h } \\
\left(\mathrm{m} \mathrm{ano}^{-1}\right)\end{array}$} \\
\hline & 2015 & 2016 & \\
\hline $\mathrm{L} 1(0)$ & $11,4 \mathrm{~A} \mathrm{~b}^{*}$ & $17,9 \mathrm{AB}$ a & $4,6 \mathrm{~b}$ \\
\hline L2 (25) & $11,3 \mathrm{~A} \mathrm{~b}$ & $19,6 \mathrm{~A} \mathrm{a}$ & $5,9 \mathrm{a}$ \\
\hline L3 (50) & $10,9 \mathrm{~A} \mathrm{~b}$ & $17,2 \mathrm{~B}$ a & $4,4 \mathrm{~b}$ \\
\hline L4 (75) & $10,7 \mathrm{~A} \mathrm{~b}$ & $19,2 \mathrm{~A} \mathrm{a}$ & $6,0 \mathrm{a}$ \\
\hline Dms colunas & 1,9 & & \\
\hline Dms linhas & 1,5 & & \\
\hline
\end{tabular}

Ao que tudo indica, apesar do maior dispêndio energético das plantas, visando a recuperação dos danos sofridos, o crescimento em altura foi pouco afetado pela ação do gado leiteiro, isso apoiado ao fato da grande rusticidade dos materiais genéticos de Eucalyptus sp. que, quando implantados com boa silvicultura, como foi o caso, com preparo do solo, adubação, controle de formigas, entre outros fatores importantes, têm plena capacidade de, na escala de alguns meses ou anos, recuperarem-se dos danos sofridos e continuarem a crescer de forma adequada.

$\mathrm{Na}$ avaliação dos danos causados pelo gado leiteiro, realizada em fevereiro de 2015, foi possível constatar a grande ocorrência de danos de nível alto nas linhas L1, L3 e L4, mostrando que a ocorrência de danos mais severos, nas árvores, por parte do gado leiteiro, não ocorre somente nas linhas mais próximas à entrada do gado na área, mas de forma aleatória em toda a área (Tabela 3). Apenas a L2, na avaliação de
2015, apresentou menor proporção de danos de magnitude elevada, ocorrendo mais danos de nível médio e baixo, os quais foram minoria nas demais linhas.

Tal constatação denota, fazendo-se uma relação entre a influência dos danos causados no crescimento em diâmetro, que essa influência não é devida somente aos danos mais drásticos, mas que também os danos de nível médio e baixo podem influenciar no DAP.

Em relação ao potencial de recuperação do eucalipto Grancam, após a ocorrência de danos, todas as linhas apresentaram boa recuperação entre as duas avaliações, mostrando que as árvores do híbrido conseguiram, em um espaço de tempo de 23 meses entre a ocorrência do dano e a última avaliação, avançar dos níveis de danos mais elevados para os mais baixos. Nesse aspecto, destaca-se a variação ocorrida na L3, onde ocorreram 100\% de danos altos em 2015, porém em 2016 os danos que prevaleceram foram médios e baixos. 
Tabela 3 - Distribuição relativa (\%) da quantidade de árvores, conforme o nível de danos causados pelo gado leiteiro, em função da distância da linha de plantio ao local de entrada de animais e a recuperação dos danos entre os anos de 2015 e 2016. Table 3 - Relative distribution (\%) of the trees quantity according to the damage level by the dairy cattle, in function of the distance of the planting line and the place of animal entrance and the recuperation of the damage between the years 2015 and 2016.

\begin{tabular}{ccccccc}
\hline \multirow{2}{*}{ Distâncias (m) da entrada dos animais } & \multicolumn{3}{c}{ Fevereiro/2015 } & \multicolumn{3}{c}{ Julho/2016 } \\
\cline { 2 - 7 } & Alto & Médio & Baixo & Alto & Médio & Baixo \\
\hline L1 (0) & 70,0 & 10,0 & 20,0 & 0,0 & 46,7 & 53,3 \\
L2 (25) & 10,0 & 40,0 & 50,0 & 6,7 & 20,0 & 73,3 \\
L3 (50) & 100,0 & 0,0 & 0,0 & 6,7 & 66,7 & 26,7 \\
L4 (75) & 80,0 & 10,0 & 10,0 & 13,3 & 46,7 & 40,0 \\
\hline Média & 65,0 & 15,0 & 20,0 & 6,7 & 45,0 & 48,3 \\
\hline
\end{tabular}

Essa mudança das árvores entre os diferentes níveis de danos mostra que o híbrido em questão tem grande rusticidade, assim como a maioria dos materiais genéticos de Eucalyptus sp., com bom potencial de indicação para ser usado em sistemas silvipastoris, uma vez que consegue se recuperar de danos em um curto espaço de tempo, com perdas de menor significância em crescimento.

Obviamente que, apesar desse rápido processo de recuperação, uma parte das árvores que sofreu danos de nível alto, em função da exposição do lenho e alguma incidência de brocas e fungos manchadores, não poderá ter sua madeira aproveitada para fins comerciais, com maior valor agregado, mas sim para biomassa energética, por exemplo, sendo, para isso, indicada a retirada dessas árvores na ocasião da realização de desbaste na área.

Estudando-se a relação entre o DAP e Ht com o nível de dano ocorrido, na avaliação de 2015, tem-se uma relação inversa entre DAP e o nível de dano $(r=-0,25(p<0,05))$, o que indica, apesar de baixa, mas significativa correlação, uma certa preferência dos animais pelas árvores de menor diâmetro. Tal fato também ocorreu em relação à altura total, com uma correlação inversa com o nível de dano encontrado ( $\mathrm{r}=$ $0,24, \mathrm{p}<005)$.

A ocorrência de danos mais elevados em árvores menores é passível de explicação pela maior facilidade dos animais em alcançar os galhos destas árvores, pela menor altura de ocorrência, e também pelo fato de que, uma árvore menor, em idade jovem, é mais frágil e susceptível a danos do que uma árvore grande. Além disso, no momento da ocorrência dos danos, ainda não havia sido realizada a primeira desrama das árvores, o que facilitou a ação dos animais, também considerando o fato de serem bovinos, animais de maior volume e peso corporal, em comparação com ovinos, por exemplo.

Tais relações entre DAP e altura total com o nível de danos nas árvores, para o ano de 2016, mostrou novamente uma relação inversa entre DAP e nível de dano $(r=-0,31, p<005)$ e a não existência de correlação entre altura total e nível de dano, demonstrando que a recuperação ocorrida também é mais lenta nas árvores menores em relação às maiores, possivelmente, em função destas últimas terem mais reservas minerais em seus tecidos e maior capacidade de crescimento secundário, recuperando-se mais rapidamente dos danos sofridos em sua casca e lenho, formando calos de cicatrização de forma mais rápida (TAIZ e ZIEGER, 2004).

Segundo Baxter e Hansson (2001), mamíferos que comem cascas de árvores procuram, em diferentes sítios e, ou espécies, equilibrar suas dietas por açúcar, proteínas ou minerais. Sendo assim, o dano dos bovinos às cascas do eucalipto Grancam desse estudo, pode atuar como um indicador de comportamento no sistema silvipastoril em estudo. Espécies arbóreas têm casca de espessura, textura e maciez distintas, além de diferenças entre compostos químicos com apelo nutricional, 
como o amido, ou que podem inibir a mastigação da casca, como óleos essenciais e taninos condensados.

Ashton (2005), estudando os danos de equinos em casca de várias espécies de eucaliptos na Austrália, constatou a existência de uma ação de seleção, por parte dos animais, por árvores individuais, mostrando que, além de variação interespecífica há também a variação intraespecífica, e que os danos foram maiores em árvores de maior diâmetro.

Contudo, para ovinos, Eason et al. (1996) sugerem que o aumento do diâmetro reduz os danos por mastigação da casca das árvores. Ainda que não conclusivo, Ashton (2005) sugeriu haver relação entre o teor de amido na casca e a mastigação da casca de eucaliptos por equinos, podendo ser um fator de seleção das árvores que terão a casca consumida.

Em uma análise dos danos causados por ovinos em árvores de eucalipto, Barbosa et al. (2013) observaram que o dano mais ocasionado foi a lesão da casca roída, seguida dos danos que lesionaram a casca e atingiram a estrutura do tronco, mas não verificaram quebra de plantas em eucaliptos com 24 meses, quando os animais se roçam nas plantas.

Porfírio-da-Silva et al. (2012) analisaram os danos causados por bovinos em espécies arbóreas usadas em sistema silvipastoril, observaram que todas as espécies sofreram danos pelos animais, sendo que o eucalipto teve cerca de $50 \%$ de danos causados, mas pouco dano comparado com a aroeira que teve $100 \%$ de danos. As lesões ocasionadas nos eucaliptos foram os danos baixos e médios, e aos que alcançaram o lenho foram observados em menor percentual.

Os danos causados por bovinos em eucalipto com três anos de idade, segundo Medrado et al. (2009), foram preocupantes, devido à idade jovem das plantas. Danos profundos, atingindo o caule foram presenciados no período de acompanhamento. Mesmo com alguns danos mais profundos, o trabalho demonstrou que, no segundo ano de acompanhamento, os danos leves foram os mais presentes, resultados estes que vão ao encontro com os obtidos no presente estudo, onde as médias entre danos médios e danos baixos são bem semelhantes entre si, após 23 meses da ocorrência dos danos.

Medrado et al. (2009) relataram que as plantas se recuperam dos danos mais leves em um intervalo de aproximadamente um ano, mas ressaltaram que a recuperação da árvore depende do dano causado, pois esta pode ocorrer de modo irregular ou ainda com uma cicatrização incompleta. Por isso, concluíram em seu trabalho que é importante trabalhar com taxas de lotação animal adequadas.

Além dos bovinos, Bernardi (2014) cita que ovinos e caprinos são os mais propensos a se alimentarem de ramos, folhas e cascas de árvores, enquanto que bovinos quebram os galhos das árvores. $\mathrm{O}$ autor relata que os animais podem danificar as árvores por meio mecânico, como o pisoteio de mudas e quebra de ramos, mastigação de folhas e até mesmo a compactação do solo pelo pisoteio. No presente trabalho foi verificado padrão semelhante de dano, onde os bovinos causaram danos, prioritariamente, através da retirada superficial de casca, quebra de galhos e folhas.

Ao analisar a causa desses danos, Bernardi (2014) cita que a falta de manejo na área é uma causa, pois tanto as árvores quanto o pasto, sem manejo adequado, favorecem que os animais procurem outras formas de alimentação. Além disso, cita que a deficiência nutricional dos animais também é fator para que os bovinos causem danos às plantas.

Assim, os possíveis fatores que levam o gado a procurar por alimento na espécie arbórea e não na forrageira podem estar ligados à qualidade e quantidade de forragem disponível aos animais, a qual está ligada, além dos fatores genéticos da seleção da espécie/variedade apropriada a cada espécie ou raça animal, à qualidade do solo, sendo esta a base para o desenvolvimento e qualidade nutricional das forrageiras que estão implantadas.

\section{Conclusões}

Os danos causados por bovinos leiteiros em 
árvores de eucalipto híbrido Eucalyptus grandis x E. camaldulensis, com 21 meses de idade, mostraram maior influência no crescimento em diâmetro do que em altura.

A capacidade de adaptação e crescimento do híbrido é alta, uma vez que, apesar dos danos sofridos, o crescimento das árvores foi comparável a árvores sem danos, tanto em altura como em DAP.

O potencial de recuperação dos danos sofridos mostrou-se elevado, havendo a passagem de danos predominantemente altos para danos médios e leves após decorridos 17 meses entre as avaliações.

Há uma relação direta entre os menores diâmetros e alturas com os maiores níveis de danos mostrando a maior susceptibilidade de árvores pequenas à ação dos bovinos.

\section{Referências Bibliográficas}

ALVARES, C.A. et al. Köppen's climate classification map for Brazil. Meteorologische Zeitschrift v.22, n.6, p. 711-728, 2013.

ASHTON, A. Bark chewing by the wild horses of Guy Fawkes River National Park, NSW: impacts and causes. 2005. $125 \mathrm{f}$. Monografia (Bacherelado em Science/Ecology), University Of New England, Armidale, New South Wales, Austrália, 2005.

BAXTER, R.; HANSSON, L. Bark consumption by small rodents in the northern and southern hemispheres. Mammal Review, v.31, n.1, p. 47-59, 2001.

BARBOSA, C.M.P. et al. Danos causados por ovelhas em árvores de eucalipto em um sistema silvipastoril distribuído em dois modelos espaciais. In: SIMPÓSIO INTERNACIONAL DE ARBORIZAÇÃO DE PASTAGENS EM REGIÕES SUBTROPICAIS, I., 2013. CuritibaPR. Anais... Curitiba-PR: Embrapa/Associação Paranaense de Empresas de Base Florestal. 2013.
BERNARDI, C.M.M. et al. Florestas plantadas de eucalipto em sistemas silvipastoris e o impacto da entrada do componente animal. Revista Verde de Agroecologia e Desenvolvimento Sustentável, v.9, n.5, p.125132, 2014.

BORGES, W.L.B. et al. Desempenho de dois híbridos de eucalipto no sistema de ILPF no Noroeste Paulista. In: CONGRESSO LATINOAMERICANO DE SISTEMAS AGROFLORESTAIS PARA A PRODUÇÃO PECUÁRIA SUSTENTÁVEL, VII., 2012. Belém-PA. Anais...Belém-PA: UFPA. 2012.

BORGES, W.L.B. et al. Integra SP - integração lavoura-pecuária-floresta no noroeste paulista. Boletim da Indústria Animal, v.71, n.2, p.192199, 2014.

CABREIRA, M.A.F. Levantamento de solos da Universidade Tecnológica Federal do Paraná - Campus Dois Vizinhos. 2015, 45 f. Trabalho de Conclusão de Curso (Graduação em Engenharia Florestal). Universidade Tecnológica Federal do Paraná - Campus Dois Vizinhos. 2015.

CARVALHO, M.M. et al. Sistemas agroflorestais pecuários: opções de sustentabilidade para áreas tropicais e subtropicais. Juiz de Fora: EMBRAPA Gado de Leite: FAO, 2001, 413p.

CARVALHO, M.M.; FREITAS, V.P.; ANDRADE, A.C. Crescimento inicial de cinco gramíneas tropicais em um sub-bosque de angico-vermelho (Anadenanthera macrocarpa Benth.). Pasturas Tropicales, v.17, n. 1, p.24-30, 1995.

DORINI JUNIOR, J.R. Produção de biomassa em diferentes materiais genéticos de Eucalyptus sp. 2015, 26 f. Trabalho de Conclusão de Curso (Graduação em Engenharia Florestal). Universidade Tecnológica Federal do Paraná - Campus Dois Vizinhos. 2015. 
EASON, W. R.; GILL, E. K.; ROBERTS, J. E. Evaluation of anti-sheep tree-stem-protection products in silvopastoral agroforestry. Agroforestry Systems, v. 34, n.3, p.259-264, 1996.

EMBRAPA-CNPS. EMPRESA BRASILEIRA DE PESQUISA AGROPECUÁRIA. CENTRO NACIONAL DE PESQUISA DE SOLOS. Sistema brasileiro de classificação de solos. $3^{\mathrm{a}}$.ed. Brasília, DF: EMBRAPA, 2013. 353 p.

FERREIRA, F. A.; MILANI, D. Avaliação de resistência de clones de eucalipto às infecções naturais de Cryphonectria cubensis, com nova metodologia. Revista Árvore, Viçosa, MG, v. 28, n. 2, abr. 2004.

FERREIRA, D.H.A.A. et al. Crescimento de clone de Eucalyptus urophylla x E. grandis em diferentes espaçamentos. Floresta, v. 44, n. 3, p. 431-440. 2014.

FIKE, J. H.; BURGER, A. L.; KALLENBACH, R. L. Considerations for establishing and managing silvopastures. Forage And Grazinglands, v.14, n.1, p.250-265, 2004.

HABITZREITER, T.L. Produção de biomassa e exportação de nutrientes de Eucalyptus grandis e E. urophylla. 2016. 97 f. Dissertação (Mestrado em Agronomia) - Universidade Tecnológica Federal do Paraná - Campus Pato Branco. 2016.

HÖGBERG, P. et al. Large scale forest girdling shows that current photosynthesis drives soil respiration. Nature, v.1, n. 411, p. 789-792, 2001.

LI, C.Y., WEISS, D.; GOLDSCHMIDT, E.E. Girdling affects carbohydrate-related gene expression in leaves, bark and roots of alternatebearing citrus trees. Annals of Botany, v.92, n.1, p.137-143, 2003.
MEDRADO, M.J.S. et al. Danos Provocados em Eucalipto por Bovinos Criados em Sistema Silvipastoril no Município de Cruzmaltina, PR. Colombo: Embrapa Florestas, 2009. 8 p. (Embrapa Florestas. Comunicado Técnico, 243).

NORDGREN, A. et al. Tree root and soil heterotrophic respiration as revealed by girdling of boreal Scots pine forest: extending observations beyond the first year. Plant, Cell and Environment, v, 1, n. 26, p.1287-1296, 2003.

OLIVEIRA, J.C.L. et al. Avaliação de dois híbridos de eucalipto submetidos à diferentes sistemas de irrigação, no município de Aquidauana-MS. In: ENEPEX: ENCONTRO DE ENSINO, PESQUISA E EXTENSÃO, 2014. Dourados-MS. Anais...Dourados-MS: UEMS. 2014.

PORFÍRIO-DA-SILVA, V. et al. Arborização de pastagens com espécies florestais madeireiras: implantação e manejo. Revista Feed e Food, v.1, n.7, p.58-62, 2009.

PORFÍRIO-DA-SILVA, V. et al. Danos causados por bovinos em diferentes espécies arbóreas recomendadas para sistemas silvipastoris. Pesquisa Florestal Brasileira, v. 32, n. 70, p. 183-192, 2012.

RIBEIRO, G.S.; RIGHI, C.A. Variações arquiteturais do eucalipto: uma comparação entre sistemas - monocultivo e sistema silvipastoril. In: V SIGA CIÊNCIA (SIMPÓSIO CIENTÍFICO DE GESTÃO AMBIENTAL), 2016. Piracicaba-SP. Anais... Piracicaba: ESALQ, 2016.

SANTOS, S.A. et al. Composição Botânica da Dieta de Bovinos em Pastagem Nativa na SubRegião de Nhecolândia, Pantanal. Revista Brasileira de Zootecnia, v.31, n.4, p. 16481662, 2002. 


\section{SCHNEIDER, P.R. Manejo Florestal:}

Planejamento da produção florestal. Santa Maria: UFSM. 2004. 493 p.

SILVA, FAS et al. The Assistat Software Version 7.7 and its use in the analysis of experimental data. African Journal Agriculture. v. 11, n.39, p. 3733-3740, 2016.

TAIZ, L.; ZIEGER, E. Fisiologia Vegetal. $3^{\mathrm{a}} \mathrm{Ed}$. Porto Alegre: Artmed. 2004. 719 p.

USDA - National Resources Consevation Service. Silvopasture: Integrating Trees, Forages and Livestock. Missouri: NRCS, 2005.

VARELLA, A.C. et al. Estabelecimento de plantas forrageiras em sistemas de integração floresta-pecuária no sul do Brasil. EMBRAPA.

<http://www.alice.cnptia.embrapa.br/bitstream/ doc/1010197/1/cap15.pdf. $>\quad$ Acessado em 23/10/2016. 